\title{
Teaching Culture in the Classroom to Arabic Language Students
}

\author{
Ahmad Abdel Tawwab Sharaf Eldin ${ }^{1}$ \\ ${ }^{1}$ Wake Forest University, Department of Romance Languages, Winston Salem, North Carolina, USA \\ Correspondence: Ahmad Abdel Tawwab Sharaf Eldin, Department of Romance Languages, Wake Forest \\ University, North Carolina, USA. E-mail: brave107@yahoo.com
}

Received: October 15, 2014 Accepted: November 12, 2014 Online Published: January 27, 2015

doi:10.5539/ies.v8n2p113

URL: http://dx.doi.org/10.5539/ies.v8n2p113

\begin{abstract}
Arabic language learning comprises of certain elements, including syntactic ability, oral capability, dialect proficiency, and a change in state of mind towards different culture or society. For teachers and laymen alike, cultural competence, i.e., the knowledge of the customs, beliefs, and systems of another country, is indisputably an integral part of Arabic language learning, and many teachers have seen it as their goal to merge the teaching of culture into the Arabic language teaching classes. It could be argued that the notion of communicative competence asserts the role of context and the circumstances under which language can be employed properly and appropriately. In other words, since the wider context of language, that is, society and culture, has been expanded, many teachers and students incessantly talk about it without knowing what its exact meaning is. In fact, what most teachers and students seem to lose is the fact that knowledge of the grammatical system of Arabic language [grammatical competence] has to be complemented by understanding of culture-specific meanings.
\end{abstract}

Keywords: culture, Arabic language, intercultural competence, society and literature

\section{Introduction}

Within the framework of globalization, international interaction and mutual relationship between different cultures show their importance. Educators and teachers have come to a consensus on the development of intercultural competence. This paper proposes that integrating Arab culture with Western culture is an effective way to enhance learners 'intercultural competence. On the basis of influential concept of intercultural competence, the paper puts forward a practical framework can help them to develop a critical awareness of self-culture and other cultures. This paper puts forward that integration of one's native culture and target culture can empower learners to experience language and culture learning at a deep level, while the development of intercultural awareness is a life-long process.

\subsection{Objectives of the Research}

This research aims to handle the following points;

1) On the basis of the cultural differences, build up student's awareness of their own native cultures.

2) To develop students' understanding of cultural differences and similarities, thatexist between the two cultures.

3) To install the idea of the importance of cross-cultural knowledge for successful language learning and teaching.

\section{Culture Definition}

This concept has different meanings to different people. In the linguistic meaning, culture is defined as the way people live. Trinovitch (1980, p. 550) focuses out that the social framework which consolidates the general and specialized conduct of individuals with their verbal and non-verbal frameworks of expressive conduct beginning from conception, and this extensive framework is described as the local culture. This procedure, which could be referred to as "socialization", readies the language learner for the linguistic and non-linguistically acknowledged examples of the cultures of the society in which he exists.

\section{Theoretical Framework on Intercultural Competence}

There are a great of literature to define and describe intercultural competence. Among them, Michael Byram and Karen Risager proposed their influential theory on intercultural competence in term of four 'savoirs': savoir-etre, 
savoir apprendre, saviors and savoir-faire. These four dimensions of skill and knowledge are defined as: First: the ability to understand and deal with cultural differences without ethnocentricity. Second: the ability to learn how others live, think, feel and communicate. Third: the knowledge of aspects of a culture, beliefs and reference points likely to be familiar to nations. Fourth: the ability to integrate the other three dimensions and interact successfully (Byram, 1997). Among these four dimensions of intercultural competence, savoir-etre is of crucial importance. It puts a particular emphasis on the mediation capacity of the intercultural speaker, the ability to juxtapose two cultures and establish intercultural communication beyond the dysfunctions and resistances which are present.

As for intercultural teaching, Humphrey (2002) has noted that the intercultural approach focuses on building awareness about people of other cultures who have different perceptions of the outside world by helping learners explore their own perceptions. The student's culture provides them with a cognitive framework for perceiving the world around them. He called the capability in one's own culture the bricks and mortar of our own most commonplace understanding. Arab cultures which focus on collectivism is different from Western cultures which asserts individualism. If students have no particular mechanism on their own culture which embraces a number of assumptions about how the Arab world is constructed, when they are exposed to other culture, there will a clear intercultural misunderstanding and miscommunication.

\section{Language and Culture}

Language and culture cannot be viewed apart since "language is not a culture-free code" (Kramsch, 1998, p. 8). The language user inevitably makes use through language of different social roles that are appropriate for a specific situation. Language learners "need to attend to variables (e.g. age, status, age, gender and education) that are especially sensitive to different cultural interpretations, which in turn, may result in miscommunication even if the intended message obeys the rules of grammar (Meier, 2003, p. 195). Kramsch (1998, p. 32) suggests that the register, the tone of one's voice, the distribution of the silence and the choice of lexical and grammatical structures are markers of identity. These details should be taken into account by any language user and culture learner who want to engage effectively in a conversation. Knowledge of these details can also offer a perspective on the complex manner of interpreting a message. Acquiring a new language also implies the learning of the conceptual structures available in the foreign language because "learners have not only to master the grammatical structures and communicative peculiarities of the new language but also, in order to be native like, they have to learn to think as native speakers do, perceive the world the way native speakers do and use the language metaphorically as native speakers do" (Kecskes \& Papp, 2000, p. 9). Since most foreign language learners are exposed to this reconceptualization in specific environment in which sociocultural knowledge is constructed with the help of course books and other authentic teaching resources, there might appear grammatical and lexical problems due to a negative language transfer from the mother tongue.

\subsection{Culture Is Language and Language Is Culture}

Culture is a style of life (Brown, 1994, p. 163). It is the frame in which we live, think, and feel each other. It is the connection that binds a group of people together. It can be defined as a blueprint that guides the behavior of people in community and is incubated in family life. It governs out behavior in groups, makes us sensitive to matters of status, and helps us to know what others expect of us and what will happen if we do not live up to their expectations. Thus, culture helps us to know how far we can go as individuals and what our responsibility is to the group.

\section{Developing Cultural Awareness in Foreign Language Teaching}

Due to its distinctive perspectives, culture has taken a critical place outside language circle and learning studies. It has been generally perceived that culture and language are utilized as a principle medium through which society is communicated. In any case, cultural aspect in language is valuable, so much prompt learners' understanding; though the advancement of individuals' social background heads them to various considerations. Most students every now and again, as it were, know the principles of language, however are not generally ready to utilize the language sufficiently. Learning language obliges a decent information of the target society which students don't appear to have, to a certain profundity. Language is a piece of the socio-culture and a society is a piece of a language. The two are unpredictably intertwined so that one can't separate the two without losing the essentialness of either language or culture (Brown, 1994, p. 164).

Then again, as the use of language all in all is identified with social and social qualities. Language is thought to be a social and social sensation. Since everyculture has its own particular social standards for discussion and these standards vary, starting with one society then onto the next, a percentage of the standards might be totally distinctive and clash with other societies' standards. Hence, communication problems may come up among 
speakers who do not know how to be involved of other cultures.

\section{Showing Culture through Language}

Scholarly interest is stimulated and fulfilled when they discover that there exists an alternate mode of interpretation to discuss emotions, needs, and when they read the writing of the foreign nation. For profundity of social comprehension, it is important to perceive how such examples work in connection to one another and to admire their spot inside the social framework. Teaching the target culture has to help the advancement of cross-cultural communicative approaches. The accomplishment of this target is conceivable with the readiness of various tools that would incorporate linguistic and non-linguistic parts of the target culture. Through this methodology, language can set up scaffolds, starting with one cognitive framework then onto the next (Seelye, 1968). The culture of individuals refers to all parts of their normal life in a group.

In the event that language is portrayed as a mode of human conduct and culture as "designed conduct", it is obvious that language is a basic constituent of society. Each culture has a remarkable example and the conduct of an individual, specifically or generally, showed that through culture is additionally interesting. Language can't be differentiated totally from the culture in which it is profoundly installed. While creating socio-cultural orientation in the Arabic classroom, it ought to be remembered that the local culture is adapted alongside the ways and disposition of the social gathering, and these ways and demeanor discover cultural patterns through the social gathering. Figuring out how to comprehend a foreign culture ought to help students of a foreign language to utilize words and sentences to comprehend levels of the language and using it suitably to suit diverse circumstances; to act commonly with persons of the other society, while perceiving and tolerating their distinctive responses, and to help speakers of different languages feel at home.

People's culture refers to all domains of their shared life in a society. In case of language is reflected as a way of human behavior and culture as specific behavior, it is clear that language is an important part of culture. Each culture has a special status and the behavior of an individual, linguistic or otherwise, manifested through that culture is distinctive as well. Language can't be divided totally from the culture in which it is profoundly implanted. While creating cultural involvement in the Arabic classroom, it ought to be remembered that the target language is adapted alongside the ways and disposition of the social gathering, and these ways and mentality discover cultural patterns through the social gathering. Figuring out how to comprehend an external culture ought to help students of another different language to utilize words and linguistic entities. It also helps to comprehend levels of language and its usage to suit distinctive circumstances; to act characteristically with persons of the other society, while perceiving and tolerating their diverse responses, and to help speakers of different tongues feel at home in the student cultural domain.

While most learners surely discover constructive profits through culturally diverse living in their learning encounters, yet there are various individuals who may encounter certain mental problems and other restraining impacts of the second society. Educators can help students to transform such an experience into one of expanded cultural knowledge. The utilization of diversions in the Arabic classrooms can help the learners overcome social weakness and it enhances the style of culturally diverse interaction, while in the meantime it gives chances to oral correspondence. Various different strategies, for example, readings, movies, recreations might be utilized by language instructors to help them in the cultural assimilation in the classroom.

Teachers can assume an important part in helping learners go through phases of cultural assimilation, while showing the culture at a particular point. Initially, language equivalence can likewise be given so as to improve learning process. The application of culture-based exercises should be used as a part of the classroom activities to help learners get to be acquainted with the target culture. The exercises and the materials ought to include the cultural values of the target language, which is intended for each level. A socio-cultural arrangement normally starts at the early stage with talks of the day by day life of the peer group in the other language about their families, their living conditions, their school, their relations with their companions, their recreation time exercises, the celebrations they praise, the functions they experience, dating and marriage traditions. At middle and progressed levels, consideration may be attracted to topographical variables and their impact on everyday living, major important periods, how the general public is sorted out, generation, transport, purchasing and offering, parts of city and nation life, the historical backdrop of workmanship, music and film etc.

\section{Raising Cultural Awareness through Literature}

The individual who learns Arabic language without learning the culture may have a risk of turning into a familiar trick of not being involved in the culture. The significance of upgrading intercultural capability alongside verbal knowledge is the cornerstone for the students interacting strongly with individuals from different countries. Indeed, what is viewed as proper in one society is generally unseemly in the other. Today, it is generally 
acknowledged that writing in the classrooms might be a medium to transmit the culture of the target language. Moreover, writing in the classroom can give an effective apparatus for the progress of the students' progress.

\subsection{The Signification of a Text}

Texts create a 'homogenized item in which the data gets to be weakened' (Mckay, 1982). Mckay (1992) offers two results: select simple writings as per students' comprehensibility, in light of vocabulary trouble and syntactic unpredictability, or select writing suitable to students' age. It gives a rich ground of real entry of culture and depicts the external world in a contextualized circumstance. It also implies a way that prompts a deep look on the external culture.

\subsection{Introducing Literature in the Classroom}

It is continually fascinating to know the amount an individual thinks about something. More often than not students like difficulties, so this is a decent source that needs to exploit when confronted with writing. Teachers can begin by asking their students to answer a short test about renowned films which are focused around well-known books, or about the most recent and most celebrated tunes or about the most recent occasions or news. A short test can act as a snare to attract students' interest or consideration towards writing. One Thousand and One Nights and so on are all bits of writing which can help in the class.

Literature circles should be based upon regular times in which students meet consistently to discuss books. Setting up writing meetings is a decent thought to enhance the notion of interaction of the students in the Arabic classroom and to invigorate social connection. Through reading and writing rings, students feel propelled to utilize the target language, particularly when they are tested, as a gathering, to comprehend and give feelings around a book with the thought of doing a particular task. Students can concentrate on the writer's style, the distinctive occasions or characters in the book, or their own particular individual encounters identified with what the book discusses.

Literature additionally engages student's creative ability, particularly when they are confronted with the dissection of fiction, show or verse. Thus, why not to exploit that? Students can make funnies, short stories, lyrics, or they can showcase a few plays, which will propel them to esteem the social setting of the bits of writing, considering and assessing the contrasts between the target language in the society and their own. Doubtlessly, literature is a voice that communicates values, convictions and indicates how we live as people, gatherings or basically individuals. Within this viewpoint, literature is the perfect instrument to show to the students some features of the Arab world. Students can find the Arab society through it. Students can acknowledge that it is so natural to comprehend the explicit ideas of the writers. It would not be troublesome for them to acknowledge how thoughts are passed on through the entire literary books. While reading and discussing any literary book, students can differ and show deep arguments about specific plans communicated in the distinctive books. In some cases, teachers ought to be mindful that certain literary portrayals may not be present reality.

It is truly clear for the students and for teachers to observe the cultural background those surfaces by basically reviewing or reading a book. Exercises ought to help instructors to include their students in the learning methodology. Thus, teachers need to pick the exercises painstakingly. However, some instructors may feel that certain literature books are simply not for them. All in all, raising cultural orientation through literature is an incredible open door for the students to expand their reality information, as they will have entry to a mixture of connections, which are inexorably identified with society. By raising cultural dimensions, students won't just move toward openness to differing cultural features. Yet, they will likewise create diverse relations to comprehend and cooperate successfully with individuals of different cultures of the world. Students may not be aware of the social and cultural problems facing the Arab society, as well as being informed about the latest political issues in that country. Teaching cultures should not be separate from other forms of cross cultural communication. It is a field of study that looks at how people from differing cultural backgrounds communicate in similar and different ways among themselves, and how they endeavor to communicate across cultures.

\section{What Should the Learners Do?}

$\checkmark \quad$ To get culturally aware in the language classroom, learners should:

$\checkmark \quad$ Work with authentic materials derived from the communities, who use the language,

$\checkmark$ Be able to contact with the native speakers of the language, from these contacts and materials they will know the similarities and differences between their own and the second culture,

$\checkmark$ Get a quasi-identity with the people of the second culture,

$\checkmark \quad$ Use this knowledge to develop a more objective view of their customs and ways of thinking. 
$\checkmark \quad$ Make the second language teachers pledge to take more responsible role in presenting cultural aspects.

$\checkmark \quad$ Identify the subtle differences in their own culture when compared to the culture of the second language they are learning and behavioral modification exercises can be given in the class.

\section{Role of Culture in Different Language Teaching Approaches and Methods}

For quite a long time, numerous thoughts and viewpoints concerning language showing that part of the society is to show the influence of culture and to strengthen this idea through the historical backdrop of remote language education. It is clear that each system in language instructing is a result of its times and it does have an impression of the prerequisites forced upon the language education. Long-Fu (2001) contends a number of the components which are involved in language learning process including: a continually propelling society which makes new parts for language in the public arena, the advancement of social sciences, and new destinations of language learning. Stern (1983) considers language learning as a craftsmanship which through the ages has sought after three real goals: social (dialect as a manifestation of correspondence), imaginative scholarly (language as a vehicle for creativity), and philosophical. He keeps up that these expansive points have, in distinctive periods ever, been underlined in various ways.

The recent surveys shows that distinctive methodologies to language and culture approached the issue of the mix of society in language educating in different ways, underlining diverse parts of society to be incorporated in their instructing project. In this part, I am going to make an agreeable picture of how culture and society have been seen under different circumstances and through the eyes of distinctive methodologies all through the historical backdrop of outside language instructing. Transferring the cultureto the students ought to be focused around different strategies, such as the followings:

\subsection{The Direct Method (DM)}

Because of the advances in science and innovation, and with the development of methods for transportation, the establishment of social and cultural dimensions of language learning was laid (Long-Fu, 2001). Students need to manage genuine circumstances in light of the fact that they needed to be exposed to different nations and work together there. Thus, their disposition to learning a foreign language changed. This prompted the appearance of the Direct Method (DM) pushed by such teachers as Berlitz and Jespersen. This strategy got its name from the way to be passed on specifically in the target language through the use of visual tools with no plan of action to the students who are learning language and culture. One of the fundamental attributes of this strategy is that the utilization of culturally arranged pictures makes students mindful of a portion of the ordinary circumstances they may experience in the foreign society.

Larsen-Freeman (2000) expresses that society in DM comprises of the historical backdrop of individuals who talk the target dialect, the geology of the nation or nations where the language is talked, and the data about the everyday lives of individuals who talk the language. Long-Fu (2001) keeps up that DM distraction with society is connected with little "c" society at the starting stages and huge "C" society at the progressed stage. He contends the most essential reason in educating of language in DM may be considered as the right to gain entrance to the best considerations and foundations of a foreign country, such as its writing, society and the soul of the country in the vastest feeling of the expression. Notwithstanding, as Long-Fu (2001) states, the absence of a decently characterized socio-phonetic and socio-social hypothetical premise made the education of social substance accidental and subordinated to the educating of language in this strategy.

\subsection{The Cognitive Approach}

In this approach, the culture learner is supposed to get the skill in a serious way as an important essential element to the performance skills (Long-Fu, 2001). The social introduction of language, reflected by the Cognitive Approach, nonetheless, is not as clear as in the past systems; however it is clear the cognitive therapists in the late 1960s, put incredible vitality on significance and association of essential knowledge in the learning procedure (Omaggio, 1986).

\subsection{The Communicative Approach}

Finocchiaro and Brumfit (1983) keep up that Communicative Language Teaching (CLT) accommodates the certifiable language use in a mixture of socio-cultural circumstances in which the steps of articulation, vocabulary, language structure and society are chosen and reviewed as indicated by their necessity in genuine correspondence. The Communicative Approach expects to place remote language learning in an unmistakably characterized social and cultural connection in accordance with the socio-linguistic perspective that language is by and large affected by the general public, money making concerns, society and the individuals who use it too (Long-Fu, 2001). He portrays the linguistic capability as incorporated by four sections: verbal knowledge, 
discourse knowledge, socio-cultural competence, and essential competence.

\subsection{Cooperative Language Learning (CLL)}

Classroom exercises permit learners to utilize their diverse understandings of how the world works, prompting stronger individual ties between cultural aspects, and the characterized individual personalities, and a more prominent feeling of involvement in the learning group. CLL can help students feel less detached and creates a more powerful classroom society. The coordinated effort towards a typical objective assumes an important part in their enthusiastic and linguistic advancement as an essential part of a culture learning class (Murphey \& Asaoka, 2006). CLL is a philosophy of pushing students to proceed with the helpful learning process from the classroom and school setting into bigger community around them.

Notwithstanding, as Byram (1997) contends, to characterize cultural competence to a great extent as far as sociolinguistic standards of a specific group is by all accounts limiting intercultural correspondence. This is on the grounds that such a model overlooks the social personality of the learners in any intercultural open occasion. Byram (1997) rather proposes a language for intercultural comprehension measurement that should be applied in the classrooms which will be clarified in the following segment.

\section{Strategies for Teaching Culture in Class}

As technology has changed the way communication is conducted, teachers of cross cultural backgrounds can help students to build their understanding of communication and they can employ culture in developing curricula for their classes. They can achieve this by adopting effective communication strategies in dealing with specific cultural groups. Arabic Language students must achieve a sound understanding of a communication model or process beyond the mere sending and receiving of messages. In addition to the message's content, the intent of the message must be understood. This becomes even more important when communication occurs among peoples of different nations and cultures. Often, the intended meaning is lost or simply misinterpreted. Thus, when curricula are designed to help students learn more about intercultural relations and communication, it can help them to practice the language in a very cultural mode. The following strategies will help students become more effective intercultural and international communicators.

First Strategy: students should understand their own cultural values and assumptionsabout other cultures

Given that culture influences how we communicate, students should conduct a candid assessment of their cultural ethics. How do those ethics influence how they perceive other cultures? Has that perception led to positive or negative behaviors towards members of other cultures?

Second Strategy: students should develop competence in language, social relationships, and respect for other cultures.

Competence in a foreign language increases job opportunities in business and industry. However, that knowledge should be combined with an understanding of the business protocols in the culture in which you practice. For instance, it is necessary to understand the importance of status/position when communicating with a professor in Egypt. Understanding or respecting the social relationships of other cultures is important. For instance, a woman would not be welcome at a Diwan'niya, a social gathering for men in most Arab countries, because of the separation of the sexes. In Western culture, it is normal for female and male colleagues to mingle outside of the work environment.

Third strategy: students should be guided to understand the nonverbal cues and the cultural context in which communication unfolds.

In some cultures, nonverbal cues are as important as verbal cues. For example, in Egypt it is considered rude to shake hands with someone without standup. It is equally rude in Nigeria to give or accept a gift with the left hand. In Nigeria, the tone, place, and the relationship between two people determine how communication is interpreted. For instance, it is acceptable for two friends to address each other as "You silly old goat."

Fourth strategy: students need to realize that developing a global attitude is imperative.

However, this should be balanced by the students' willingness to be adaptable to changes and ambiguity. We live in a global village. Many students might find themselves employees of international companies, or may be required to travel to the Middle East for studying or business. Flexibility and coping with uncertainty and ambiguity of other cultures will enhance one's ability to conduct business successfully. In Saudi Arabia, meals are served in a large tray, and everyone eats with their fingers. Your host may be offended if you ask for a separate plate for your meal. In Egypt, expect yourhosts to inquire about your family and to offer a meal before a business meeting. To develop and enhance mutually beneficial relationships with international and intercultural 
audiences, students should also focus on key public relations campaign strategies. These include an understanding of the communication challenges in the host country, such as the audience, the message, and media discourse.

Fifth strategy: awareness of how language would be understood by your host culture is imperative.

Most Muslim and Arab societies use the word meat to refer to beef. So, students should tailor their language to mirror the cultural perspective of the audience. Additionally, to avoid mistakes in using the language, collaborate with native speakers who understand not only the language, but also the context in which the language is used.

Sixth strategy: understanding the media discourse in the culture or country that you want to reach is vital.

It is advisable for the students to work with local agencies to gain access to the local media, adapt, and disseminate culturally appropriate materials to the audience. The success of Al Jazeera channel demonstrates the effectiveness of the strategy of collaboration and targeted messages, and students might take this channel as a sample to understand more about the media discourse.

\section{Conclusion}

In developing cultural awareness in the classroom, it is important that we help our students distinguish between the cultural norms, beliefs, or habits of the majority within the community and the individual or group deviations from some of these norms. Students should be able to discuss their native culture with their foreign-speaking friends at the same time that they are provided with a real experiential content. The development of an awareness of socio-cultural and socio-linguistic differences that might exist between the students' first language and the target language is necessary. Such awareness often helps explain to the Arabic language learners to be able to interact in a very communicative method and achieving their target of using the language.

\section{References}

Brown, H. D. (1994). Principles of Language Learning and Teaching. Prentice Hall Regents.

Buyukkantarcioglu, N. (2000). The Role of Cross-Cultural Understanding in Foreign Language Teaching (pp. 219-229). Erzurum Üniversitesi, Eğitim Fakültesi Dergisi.

Byram, M. (1989). Cultural Studies in Foreign Language Education. Clevedon: Multilingual Matters.

Byram, M. (1997). Cultural Awareness as Vocabulary Learning. Language Learning Journal, September(16), 51-57.

Byram, M. (1997). Teaching and Assessing Intercultural Communicative Competence. Clevedon: Multilingual Matters.

Byram, M., \& Risager, K. (1999). Language Teachers, Politics and Cultures. Multilingual Matters Ltd.

Celece-Murcia, M. (1991). Teaching English as a Second or Foreign Language. Boston: Heinle and Heinle Publishers.

Crystal, D. (1992). An Encyclopedic Dictionary of Language and Languages. Blackwell, USA.

Damen, L. (1987). Culture Learning: The Fifth Dimension in the Language Classroom Reading. MA: Addison-Wesley.

Finocchiaro, M., \& Brumfit, C. (1983). The Functional-Notional Approach. Oxford: Oxford University Press.

Humphrey, D. (2002). Intercultural communication; a teaching and learning framework. Paper presented at the conference "Setting the Agenda", University of Manchester, Manchester.

Kam, L. (2005). Gathering cultural knowledge: Useful or use with care? In J. Carroll, \& J. Ryan (Eds), Teaching International Students (pp.17-25).

Kecskes, I., \& Papp, T. (2000). Foreign Language and Mother Tongue. Mahwah, NJ: Lawrence Erlbaum.

Kramsch, C. (1998). Language and Culture. Oxford University Press.

Larsen-Freeman, D. (2000). Techniques and Principles in Language Teaching. Oxford: Oxford University Press.

Long-Fu. (2001). Teaching English cultural background: Introducing the target culture in the Chinese secondary school English classes (Ph.D. thesis, University of Tampere).

McKay, S. (1982). Literature in the ESL classroom. TESOL Quarterly, 16(4), 529-536. http://dx.doi.org/10.2307/3586470

McKay, S. (2001). Literature as Content for ESL/EFL. In M. Celce-Murcia (Ed.), Teaching English as a second 
or foreign language (pp. 319-332). Boston: Heinle \& Heinle.

Meier, A. J. (2003). Posting the banns: A marriage of pragmatics and culture in foreign and second language pedagogy and beyond. In G. A. Fernandez, F. A. Martinez, \& J. U. Esther (Eds.), Pragmatic Competence and Foreign Language Teaching (pp. 185-210). Publicacions de la UniversitatJauame I, Castello.

Murphey, T., \& Asaoka, C. (2006). Creating cultures of intensive collaboration. In M. Apple \& E. Shimo.

Omaggio, A. (1986). Teaching language in context: Proficiency-oriented instruction. Boston, MA: Heinle and Heinle Publishing Inc.

Poyatos, F. (1983). New Perspectives in Nonverbal Communication. Pergamon Press. England.

Seelye, H. H. (1968). Analysis and Teaching of the Cross-Cultural Context. In E. M. Birkmair (Ed.), The Britanica Review of Foreign Language Education (Vol. Chicago, pp. 37-81).

Tang, R. (1999). The Place of "Culture" in the Foreign Language Classroom: A Reflection. The Internet TESL Journal, $V(8)$.

Trivonovitch, G. J. (1980). Culture Learning and Culture Teaching. In K. Croft (Ed.), Readings of English as a Second Language. Cambridge, Mass: Withrop Publisher Inc.

\section{Copyrights}

Copyright for this article is retained by the author(s), with first publication rights granted to the journal.

This is an open-access article distributed under the terms and conditions of the Creative Commons Attribution license (http://creativecommons.org/licenses/by/3.0/). 